\title{
Communicating adaptation with emotions: the role of intense experiences in raising concern about extreme weather.
}

\author{
$\underline{E l e f t h e r i a ~ V a s i l e i a d o u ~}^{1,2}$ and $\underline{\text { Wouter J. W. Botzen }}^{1}$
}

\begin{abstract}
Adaptation to extreme weather is often considered as having a low urgency and being a low priority governance option, even though the intensity of extreme weather events is expected to increase as a result of climate change. An important issue is how to raise an adequate level of concern among individuals, policy makers, and broader decision makers in companies and organizations so that adaptation to extreme events becomes mainstream practice. We conducted 40 indepth interviews with individuals from different sectors in The Netherlands to identify the different types of experiences with extreme events, as well as the relationship between such experiences and the level of concern about extreme weather. Our results indicate that individuals who have experienced an intense, lifethreatening event have a significantly higher level of concern than those without such an experience. Professional experience and secondhand experience through participating in information events do not significantly affect the level of concern about extreme events. This suggests limited intervention possibilities for communication of adaptation, as well as for raising support for adaptation measures. Framing adaptation measures in relation to personal circumstances and emotions during extreme events could help raise concern about extreme weather events, as well as societal support for adaptation measures.
\end{abstract}

Key Words: adaptation; availability heuristic; extreme weather; risk communication; risk perception

\section{INTRODUCTION}

Climate change is expected to increase the frequency and the severity of extreme weather events, such as extreme precipitation, heat waves, and extreme drought, but possibly also storms, tornadoes, and hail (van Dorland et al. 2011). Even though uncertainties around these projections are considerable, adaptation to extreme events is considered a priority nowadays, given the potentially high costs of damages from extreme weather and climate change (van Dorland et al. 2011). Several climate change adaptation plans are currently being designed and implemented by national and local governments (Aerts et al. 2011). Individual citizens and decision makers in the private sector play a key role in such plans for the support for and implementation of climate change adaptation measures. For example, a recently conducted study about increasing the resilience of New York City to flooding and climate change has recommended implementation of stricter flood-resistant building codes and inclusion of climate change risks in urban planning considerations (Aerts and Botzen 2011). At the same time, the extent to which adequate adaptive responses will emerge by individuals and communities remains unclear. An important issue is how to raise an adequate level of concern among individuals, policy makers, and broader decision makers in companies and organizations so that adaptation to extreme events becomes mainstream practice.

Although some decision makers are proactive about adaptation to extreme events, it seems to be a low urgency and low priority policy option for many others (Bulkeley 2010). This lack of attention to adaptation may be due to a lack of understanding or poor perceptions of climate change risks relative to other risks among a large part of the population (Leiserowitz 2005, 2006, Weber 2006, Reynolds et al. 2010). Climate change is a very complex problem for individuals (Swim et al., 2011b), which implies that understanding the cognitive dimension and perceptions is very important for climate change adaptation. In a recent study, the absence of perceived importance to the public and lack of public awareness or demand to take action were among the main hurdles to implementation of adaptation projects (Archie et al. 2012). As Dupuis and Knoepfel (2013) note in their contribution to this special issue, "whereas adaptation has appeared on the political agenda in many countries, implementation has rarely occurred."

Environmental consultants and scientists have been advocating for and organizing information workshops and events and have been working with communications media in order to raise awareness about adaptation and provide information on extreme weather, climate change, and their risks (Mozumder et al. 2011). However, there is hardly any robust evidence of how effective these events and workshops are and of what, if any, their impact is on the participants' concern about extreme weather events and adaptation thereof. This study examines the factors influencing concern about extreme weather events, which is a relevant research topic given that concern about extreme weather events is the first step toward prioritizing and accepting adaptation measures to such events. The latter follows from protection motivation theory, which postulates that a sufficiently high risk perception or "threat appraisal" is an important precondition for individual motivations to protect against a hazard (Rogers 1973, 1983).

Previous research has shown that individual risk perceptions may deviate considerably from expert risk assessments and that risk perceptions are to a large degree shaped by personal experiences with the hazard (Slovic 1987, 2000). Our starting point for this study is that individuals experience extreme weather events in a variety of contexts, which is expected to influence the extent to which they feel concerned about them. Such contexts may involve an intense personal and maybe traumatic experience; the professional context, which may relate to addressing extreme weather events and their impacts; a secondhand experience in a communication or information event such as a workshop or seminar; a vulnerable context related to one's own position, e.g., older people are generally more vulnerable to the impacts of extreme weather events. Some of these contexts can be influenced by communication aimed at raising concern among individuals 
for climate change risks, whereas others are external and cannot be influenced, for instance, intense personal experiences.

We conducted a series of indepth interviews with 40 individuals in The Netherlands in order to identify what are the different types of experiences of individuals with extreme weather and to what extent these types of experiences affect their concern about extreme weather. The interviewees came from two broad professional backgrounds: namely, professions that primarily respond to extreme events, such as crisis management and public health; and professions that are primarily affected by extreme events, including tourism and transportation. As most previous research is either of a qualitative nature or consists of quantitative surveys, we combine qualitative analysis of the interview data with quantitative analysis of survey data to probe deeper in the types of individual experiences but also to provide some measurable impact on concern.

The results suggest that secondary experience, as in participation in information and communication events, does not always affect the level of concern of the participants nor does professional experience. An intense, life-threatening personal experience was the only significant determinant of concern about extreme events. This finding is consistent with the literature on the "availability heuristic," which implies that individuals judge a hazard as risky if it is easy to imagine or recall, for example, because of previous experiences with the hazard (Kahneman et al. 1982). Our findings imply that raising awareness about adaptation to extreme events through workshops may not always lead to an increased sense of concern. Nevertheless, communicating adaptation measures in relation to personal circumstances and emotions about extreme weather events could raise the level of concern about such events, and thus legitimacy and support for adaptation.

\section{LITERATURE}

Understanding of individuals' perceptions of, or concern about, extreme weather events is very important for designing and implementing climate adaptation policies. Individual judgments of climate change-related risks can determine the perceived legitimacy as well as compliance with adaptation policies (Peacock et al. 2005). Moreover, individual perceptions of natural hazards are important factors influencing decision making about undertaking measures that mitigate these risks (Burn 1999, Flynn et al. 1999). For example, high flood-risk perceptions of individuals are related to a high demand for flood insurance (Botzen and van den Bergh 2012,a,b). Similarly to the household level, perceptions of extreme weather risks at the organizational level can be expected to be an important factor influencing the resources that an organization is willing to devote to climate change adaptation.

\section{Concern about Extreme Weather Events}

In evaluating hazards, people commonly rely on intuitive risk judgments, called risk perceptions, which may differ considerably from technical or expert assessments of risk (Slovic 1987, 2000). Technical assessments of risk could be seen as objective risk assessments, which are often made based on calculations using empirical information on probabilities and damages of adverse events. Risk perceptions are a combination of cognitive responses (beliefs and thoughts about the risk) and emotional responses (risk as feelings or concern). Individual risk perceptions are subjective and are often based on heuristics, which are decision rules or processes that individuals adopt to reduce the complex task of assessing risk to simpler operations. Tversky and Kahneman (1974) identify a variety of such heuristics, of which mainly the availability heuristic is important here. Availability in this respect refers to situations in which people assess the probability or risk of an event by the ease with which instances or occurrences can be brought to mind. These heuristics are usually effective, but they also lead to systematic (predictable) errors in judging risk, or cognitive biases. For example, there is evidence that individuals tend to overestimate smaller common risks compared with large and exceptional risks (Sjöberg 1999, 2000).

In his work, Nobel Prize laureate Daniel Kahneman summarizes decades of behavioral decision research and identifies two modes of thinking that drive individual behavior, which are called system 1 and system 2 (Kahneman 2003). System 1 operates automatically and quickly with little or no effort and no sense of voluntary control. In contrast, system 2 allocates attention to the effortful mental activities that demand it, including complex calculations. With respect to decision making under risk, system 1 includes emotional reactions and feelings about risks which, for example, have been acquired by personal experiences with a hazard. System 1 thinking has been associated with biases and systematic errors, especially if decisions are to be made about unfamiliar topics. Such errors can be important for decision making about natural disasters and climate change risks because experiences with such risks are limited for individuals due to the low-probability nature of these risks. System 2 thinking about risk entails a more systematic and effortful evaluation of the information available and may be typified as the standard rational economic model of behavior. System 2 has some ability to change the workings of system 1 , but system 2 thinking is hard and it comes at a cost and may, therefore, not be applied in all instances.

Related to environmental psychology, the formation of environmental risk perceptions and factors affecting them has also been studied. Cultural theory postulates that four archetypal views on the vulnerability of nature (rooted in worldviews) can be distinguished, which are related to environmental concerns (Poortinga et al. 2002). In particular, nature capricious (fatalist) and nature benign (individualist) views are related to low environmental concerns. Nature tolerant (hierarchist) and nature ephemeral (egalitarian) views are related to, respectively, average and high environmental concerns. Poortinga et al. (2002) show that these views and environmental concerns are related to different preferences for risk management strategies. For example, individuals with a low environmental concern have the highest preference for market-oriented strategies, whereas individuals with a high environmental concern prefer government regulations.

An alternative theory that explains environmental behavior and environmental risk perceptions is value-belief-norm (VBN) theory (Stern 2000), which explains how behavior results from a chain of different personal values (biospheric, altruistic, and egoistic) and beliefs (about ecological worldviews, adverse consequences for valued objects and ability to reduce threat) as well as proenvironmental personal norms. According to VBN, the influence of risk perception on behavior takes place indirectly via 
responsibility beliefs and the activation of a personal norm to act. In VBN theory, personal experience of effects of climate change could influence environmental values by resulting in a stronger ecological worldview, which increases risk perceptions and willingness to take action (Whitmarsh 2008). Another theory that explains behavior using perceived social norms, attitudes, and perceived behavioral control is the theory of planned behavior, which additionally describes the importance of intentions to perform a behavior (Ajzen 1991).

In this study, we investigate whether or not experience of extreme weather events has an impact on concern about these events. Such experiences can, for example, be a firsthand, personal experience with a heat wave, a threatening hurricane, or a blizzard, which may have caused the individual to feel more concerned in general about extreme weather events because they are more sensitive toward it and feel more vulnerable to extreme weather. Such an emotional response to risk based on past experiences is related to system 1 thinking (Kahneman 2003), or related to risk as feeling (Loewenstein et al.2001). Another type of experience is secondary experience, through obtaining information about extreme events in a formal or informal setting, without firsthand experience. This study examines whether or not participation in an information event influences concern about extreme weather risks, which is related to system 2 thinking. Furthermore, concerns about extreme weather may be shaped by a specific type of professional experience, such as, e.g., a crisis manager has a professional relationship to extreme events. It may be that professionals engage more in system 2 thinking about risks than do lay people, although research on this topic is not promising and suggests that experts may be prone to similar biases as the general public (Fischhoff et al. 1982).

\section{Information}

We aim to examine whether different levels of concern among interviewees correlate to differences in levels of being informed. One may expect that the more informed one is about extreme weather and its impacts, the more concerned one would be about it. Therefore, the amount of information individuals possess is one of the determinants of perceived dangerous climate change (Dessai et al. 2004). More recently, a review of flood risk perception research indeed observes that a lack of knowledge about floods is associated with lower individual flood risk perceptions (Kellens et al. 2012). Both articles consist of systematic review of previous findings.

Nevertheless, these findings are not unequivocal. In another empirical study, the (self-reported) level of information about climate change was identified as a factor influencing concern with respect to climate change (Kellstedt et al. 2008), but in an unexpected way: the more individuals felt they were informed about climate change, the less concerned they were. The authors explain this by suggesting that those more informed about climate change probably also trust science and scientists to find a solution for climate change. In a more recent study, using quantitative analysis of broad survey data from U.S. adults, high degrees of scientific literacy and numeracy were associated with a small decrease in the perceived seriousness of climate change risks (Kahan et al. 2012). In addition, there is indication that the level of education has a mitigating effect on aspects that increase climate change risk and that it plays a role in people's capacity to adapt, more so for women than for men (Wamsler et al. 2012). Both studies make use of quantitative analyses of broad survey data.

The role of the media in providing information related to climate change or extreme weather also needs to be mentioned here, especially because the media often use more emotional language. In an empirical study, exposure to a specific information source, namely Al Gore's movie "An Inconvenient Truth," resulted in raising levels of knowledge about climate change and level of concern about climate change (Nolan 2010). This latter study used objective measures of knowledge about climate change and found a positive relationship between level of knowledge and level of concern in two small-N empirical studies. Similarly, a study of the effects of "The Day after Tomorrow" by Lowe et al. (2006) showed that viewers were significantly more concerned about climate change and other environmental risks immediately after the movie. Focusing on more long-term impacts, however, may give a different picture. The longitudinal panel study, which examined the impacts on UK viewers of a climate change movie, "The Age of Stupid" (Howell 2014), showed that the heightened levels of concern and sense of urgency to act initially generated by the movie did not measurably persist over the long term.

Because of these different results obtained from previous work, we wanted to combine indepth understanding of the topic with robust statistical analysis with measurable indicators. We decided, thus, to combine qualitative and quantitative analyses of interview data because, to our knowledge, such a combination has never been conducted before on risk perceptions for adaptation.

\section{Participation in Information Events}

One way through which information about extreme weather can be obtained is by participation in information or communication events, workshops, and seminars that are being organized for professionals and other citizens. Especially in The Netherlands, where the risk of flooding is high, such events are not uncommon (Terpstra et al. 2009). Within the context of climate change and high political awareness about it, there are even more such information events nowadays. Often the implicit aim of the organizers of such events is that they raise awareness and make participants feel more concerned about extreme events. Thus, one would expect that participants in such information events would be more informed about extreme events and would also feel more concerned about extreme weather and its impacts. However, a recent review of flood risk perception research argues that very few studies have explicitly examined effects of flood-risk communication on individual risk perceptions (Kellens et al. 2012). An exception is a study analyzing the effects of a floodrisk communication program in The Netherlands using workshops and focus groups (Terpstra et al. 2009). In contrast to expectations, risk communication had only very weak effects on the flood-risk perceptions of individuals.

\section{Professional Experience}

A big part of individuals' experience comes from their involvement in a specific job. Extreme weather events and their impacts pose risks for many professionals, and especially for professionals who work outdoors, e.g., farmers or those in transportation. We have made a distinction between professional experience in dealing with extreme events and their risks and 
professional experience in being affected by extreme events. Individuals may feel more concerned about extreme events if they have to deal with and face extreme events as part of their jobs (e.g., firefighters or crisis managers). Or the opposite may be true: because they deal with extreme events, these individuals may feel in control of such events and thus be less concerned about them. At the same time, individuals in the transportation sector who are more dependent on weather and more affected by its extremes may feel more concerned.

This possible relationship between professional experience and concern about extreme weather has not been investigated by any empirical study, to our knowledge. In a series of interviews with climate change experts about their perceptions of climate change, no influence of institutional affiliation (professional experience) on these perceptions was found, probably because the interviewees were multi-institutional (Lowe and Lorenzoni 2007).

\section{Personal Disaster Experience}

Affective feelings are important in individual risk judgments (Loewenstein et al. 2001, Slovic et al. 2004). Individuals may have a higher risk perception of extreme weather events if such events are associated with negative feelings, which may have been caused or reinforced by personal experiences with the natural hazard (Finucane et al. 2000a, Keller et al. 2006, Botzen et al. 2009). This is related to the relevance of the "availability heuristic" in risk perception, as discussed before (Tversky and Kahneman 1973, 1974). For example, individuals who have experienced a specific disaster may find it easier to imagine that such a disaster will happen again in the future and, therefore, indicate a higher perceived risk than individuals without this experience. From a Bayesian learning standpoint, one would also expect that perceived risk increases after the experience of a disaster (Viscusi and Zeckhauser 2006). In particular, individuals may revise earlier risk beliefs upward after the experience of a disaster if it provides information that risk may be higher than initially anticipated. A practical example of the availability heuristic is that many individuals purchase flood insurance after a flood has occurred, whereas they drop this coverage after several years if they do not experience another flood (MichelKerjan et al. 2012). If experiences with a hazard are intense and personal, then they may influence levels of concern about a risk through the availability heuristic, because availability may not only influence the perceived frequency of a risk as Tversky and Kaneman (1974) described, but also concern about the risk, as would be in line with the risk as feelings hypothesis (Loewenstein et al 2001). The reason is that risk perceptions are a combination of cognitive responses (beliefs and thoughts about the risk) and emotional responses (risk as feelings or concern).

\section{METHODS}

The data analyzed in this study are obtained as part of a wider study on perceptions of different social actors on extreme weather events in The Netherlands (Vasileiadou and Botzen 2014). In this paper, we only report the results that enable us to understand how different types of experiences of extreme events affect an individual's level of concern about extreme events.

A total of 40 individuals $(N=40)$ were interviewed. The respondents were selected from different sectors, all of which are immediately affected by extreme weather events, either through their risks or possible benefits (the number of interviewees from each sector is shown in parentheses): crisis management (5), hospitality sector (hotels, restaurants and cafes) (6), public health (6), tourism and recreation (9), urban transportation (5), vulnerable individuals (4), and water sector (6). Crisis management, public health and the water sector were selected because of their primary role in responding to any extreme weather event. Hospitality, tourism and recreation, and urban transportation are economically vital sectors in The Netherlands that are affected by extreme events. The last group, vulnerable individuals, consists of older people and people who deal with younger children and was selected because they are almost never taken into account in relevant studies, yet they are among the most affected in the case of any extreme weather event. Previous research has suggested that a person's physical location is an important determinant of climate change risk perception, especially given the fact that climate change impacts will be highly region specific (Brody et al. 2008). Most of our interviewees work in, or close to, the city of Amsterdam.

The selection of sectors was, on the one hand, related to our aim of studying adaptation governance, as we made sure all relevant sectors were involved, such as crisis management. Furthermore, we conducted theoretical sampling (Strauss and Corbin 1990). In addition, we tried to achieve a "maximum variety" within each sector by interviewing directors of institutes and regular employees alike. We contacted relevant organizations and actors from the selected sectors at random, explaining the purpose of the study and the procedure. We interviewed the individuals that were interested in participating and who contacted us back. This may have created a bias toward participants who were interested in the topic (adaptation to extreme events). Therefore, we did not select interviewees on the basis of their personal experience with extreme events, only on the basis of their professional experience The interviews took place in the period April-June 2011. We note that the preceding winter had been extremely cold in The Netherlands, especially during the month of January, with long period of snowfall. This may be relevant because of the availability heuristic, through which interviewees remember well weather extremes they experienced recently and assess their probability as higher (Tversky and Kahneman 1974). The interviews lasted on average $1 \mathrm{~h}$; they were transcribed verbatim.

In an open-ended question, we asked our respondents whether they had experienced any extreme weather event, and asked them to describe this experience. We conducted qualitative analysis in an iterative way on this response, looking for the broader themes of such experiences (Strauss and Corbin 1990). This analysis is reported first in the results section.

In addition, we collected information on the following variables:

- Level of concern: Measured as the answer to the question: "How concerned do you feel about extreme weather events, on a scale from one to seven?" One indicating "not concerned at all" and seven indicating "extremely concerned.". $M=3.8$; $\mathrm{SD}=1.74$

- Level of information: Measured as the answer to the question: "How informed do you feel you are about extreme weather risks, on a scale from one to seven?" One indicating 
"not informed at all" and seven indicating "fully informed" $M=4.38 ; \mathrm{SD}=1.62$;

- Participation in information events: This variable captures whether or not the individual has participated in any information workshop, seminar or event on extreme weather, its risks, and adaptation to extreme weather. This is a dichotomous variable with answers "Yes" $=16$ and "No" $=24$;

- Professional experience: This is a nominal dichotomous variable that distinguishes between professions that respond to and address extreme event risks (including water sector, crisis management, public health) $n=17$; and sectors that are vulnerable to and affected by extreme weather (older people, those working with younger children, hospitality sector, urban transportation, tourism) $n=23$;

- Sex: Earlier research indicates the "white male effect," whereby risk perception is higher among individuals who are female and who belong in a disadvantaged socioeconomic group because they are more vulnerable (Finucane et al. 2000b). We test this effect with a dichotomous gender variable with answers "Male" $=30$ and "Female" = 10;

- Intense personal experience: This variable captures whether or not the individual described an intense, life-threatening experience with extreme weather event in the past. We coded this variable on the basis of the qualitative analysis of their responses. This is a nominal dichotomous variable with answers "Yes" $=12$ and "No" $=28$.

In the statistical analysis, we treat "Level of concern" as the dependent variable and the other variables as independent. The data were inserted and analyzed in the Statistical Package for Social Sciences (SPSS). These results are reported in the second section of the results.

We use both qualitative and quantitative analysis to understand and explore the different types of experiences of individuals with extreme weather and to what extent these types of experiences affect their concern about extreme weather. In addition, we use the qualitative results as input for the quantitative analysis: the variable intense personal experience was coded as yes in those respondents who described their experiences as intense, personal, and emotional (first theme of qualitative analysis).

\section{RESULTS}

\section{Qualitative Analysis}

The ways our interviewees relate to extreme events they have experienced can be classified in three broad ways: (a) personal and emotional responses, linked to negative emotions; (b) personal but descriptive responses; (c) impersonal responses.

First, among the personal and emotional responses, the feeling of loss of control and hopelessness was prevalent.

I am scared of thunder, and more than simply scared... I have experienced thunderstorms a couple of times and I felt "it is not going well," really a feeling of "you are absolutely nothing, powerless." (Interviewee 1)

Another interviewee mentioned similar emotions in the case of extreme mist while driving in a car, especially with passengers who had been previously involved in an accident: "They transferred their fear to me, and this strengthened my feeling of despair" (Interviewee 3). In such cases, the feeling of not being able to do something to help yourself is the one that prevails. However, one respondent expressed the opposite feeling, one of willingness to overcome the natural force, in the case of a heavy snowstorm that occurred during a trip, saying tellingly: "I do not stay at home often because of the weather." (Interviewee 2)

Other respondents linked their experiences to feeling scared, especially with mist and heavy thunderstorms.

Yes, I experienced the November storm of '72. The impact of this is that I became conscious of the force of nature; it is imposing and frightening. (Interviewee 16)

Previously, I used to sail, and when you get a storm in the water that gives you a feeling of being scared, it changes your perception. (Interviewee 12)

This fear can also be in relation to experiencing extreme weather in a professional capacity. One crisis manager in the police department told us:

Then, the first thing I think of is my work. I have worked during huge storms, and we were scared also for human lives. That we really had to get out to provide emergency services. (Interviewee 38)

Most often, the weather events that were related to fear, loss of control, or powerlessness are mist while driving on the road and thunderstorms, but one respondent also mentioned snowstorms. These responses we coded as "intense personal experience" for the statistical analysis below.

The second way individuals related to their experiences was in a personal way, identifying a personal story or impact, but in a descriptive, somewhat distanced way. In that case, no emotions, negative or positive, were communicated.

Yes [I have experienced extreme weather] I was here in the office during a very bad storm and I could not go home. And one time in the palace Soestdijk, very big trees fell on the road. And last winter, with a lot of problems with the railway and long periods of heat waves in the summer. (Interviewee 34)

Sometimes such an extreme experience occurs abroad.

[I have experienced extreme weather.] Only in Montreal. At that time, I was wearing two jackets, it was -19 degrees, and I went walking wearing moon boots. The family I was staying with said I was crazy to walk with this cold. But I wanted to try it. For some time, it went well, but when I reached a government building I fainted... My hands froze to the metal of my camera while I was taking pictures. I find this quite extreme; here [in The Netherlands ], it is always more moderate. (Interviewee 35)

In these cases, the interviewees relate their personal experience and circumstances with the extreme weather event, i.e., what they had to wear, what inconvenience it brought, etc., but without 
feelings about it. In all these circumstances, the experience itself is not described as life threatening.

\begin{abstract}
Yes [I have experienced extreme weather] a hurricane in the '90s. I come from a farm, and there weather is very important; one's income depends on it. Then extreme heat, and also a hailstorm, with very hard wind, but I never that I thought I would die. (Interviewee 33)
\end{abstract}

Last is the case of respondents who briefly mention or describe the extreme events they have experienced without any reference to their personal circumstances, nor any feelings. These descriptions are very impersonal.

Yes, [I have experienced] a couple of heat waves; and a couple of years ago, an extreme hailstorm with huge stones. Also, I have experienced several thunderstorms and also flooding. (Interviewee 15)

Often these are very brief responses. In other cases, the respondents moderate their experiences themselves.

\section{$A$ heat wave or extreme rainfall is extreme weather and I have experienced such events. Of course also storms, with storm force 12. February storms every now and then. But in The Netherlands, it is not comparable to what other countries experience. Because we find 3 days above 30 degrees extreme, but that is very normal for other countries. It depends on the location. (Interviewee 16)}

In these types of responses, either several extreme weather events are listed one after the other (heat waves, storms, etc.) or a single event, which is the most easily recalled, hinting at the availability heuristic mentioned in the literature review. "Apart from this last winter that was very, very cold, no, not really" (Interviewee 20). "Yes [I have experienced extreme weather] a lot of snowfall this last winter and long periods of heat already this year, also in April or May" (Interviewee 22)

With respect to the types of weather conditions the respondents identified as extreme weather, it is noted that all different extremes came into the discussion: heat waves, thunderstorms, snowstorms, extreme cold, mist, strong winds, hurricanes, hail storms, extreme rain, winds, tornados. It is indicative that the most frequently mentioned extreme event was extreme storms, mentioned by 20 respondents, referring to either three of the themes identified above. This may reflect the prominence of and the traumatic firstor secondhand experience of the 1953 flood in the Netherlands, the result of a storm, that killed more than 1,800 individuals. The second most frequent event was extreme cold and/or snow, which was mentioned by 16 respondents. This can be related to the availability heuristic mentioned earlier, as some of the respondents acknowledged (see quotes of the previous paragraph). As a third most frequent phenomenon, a relatively recent phenomenon by Dutch standards (Vasileiadou and Botzen 2014), heat waves were also mentioned by 14 respondents, although none of them mentioned it as a life-threatening experience.

It needs to be noted here that what counts as extreme was very different for the respondents, and this was also something that occasionally was explicitly acknowledged. "Yes [I have experienced extreme weather], but everything is weather, so I find extreme a very difficult word" (Respondent 24). Another respondent also reflected on this individual understanding of extreme: "I find things extreme very easily. This winter, when I had to drive here and it was so slippery and icy, then I didn't feel at all safe on the road" (Respondent 39). Linked to this understanding of extreme weather as highly subjective, a few respondents discuss their experiences in relation to some sort of "objective" definition of extreme weather, and suggest that they have not experienced anything like that: "Truly extreme weather? No [I have not experienced it], not really. Not more extreme than this [referring to that year's snowfall and cold]." (Respondent 29)

\section{Quantitative Analysis}

In this section, we report the results of the statistical analyses in order to identify which factors influence concern about extreme weather events. First, we ran analyses using each independent variable, with concern about extreme weather as a dependent variable. Following this, we performed a multivariate regression, using all possible independent variables together in the model.

To what extent does being informed influence the level of concern?

The correlation between the scale variables of the level of information and level of concern is positive but not statistically significant (Pearson correlation $=0.221 ; p=0.183$ ). This is rather surprising because it would be expected that the more informed an individual is about extreme weather events, the more concern he or she would feel about extreme events and their impacts.

To what extent does participation in information events influence the level of concern?

One-way ANOVAs show that there is a positive relationship between participation in information events and level of concern, but it is not statistically significant $(F(1,38)=0.753 p=0.391)$. Information event participants feel on average more concerned $(M=4.09 ; \mathrm{SD}=1.81)$ than those not participating in such events $(M=3.60 ; \mathrm{SD}=1.71)$. It seems that participating in information events is not related to raising the level of concern about extreme weather events, contrary to the expectations of many organizers of such events.

However, there is a positive relationship between participation in information events and the level of information, which is statistically significant $(F(1,36)=6.161 ; p=0.018)$. Participants of information events feel on average more informed $(M=5.18$; $\mathrm{SD}=1.35)$ than those not participating in such events $(M=3.91$; $\mathrm{SD}=1.6)$. In the table below, the descriptive statistics of the analysis can be seen, including the confidence intervals (Table 1). Thus, information events may raise awareness, but not necessarily feelings of concern.

To what extent does professional experience influence the level of concern?

One-way ANOVAs between professional experience - whether or not the individual is affected by extremes or has to address extremes - and the level of concern yield no statistically significant results $(F(1,36)=0.937 ; p=0.340)$. Professionals who deal with risks feel on average more concerned $(M=4.70 ; \mathrm{SD}=$ 1.57) than those in professions vulnerable to risks $(M=4.18 ; \mathrm{SD}$ $=1.66$ ). This is a rather surprising finding, as one would expect that individuals who are more vulnerable to extreme events would be also more concerned about their impacts. 
Table 1. ANOVA results for impact of participation in workshops on level of information

\begin{tabular}{lcccccc}
\hline \hline & & & & & \multicolumn{2}{c}{$95 \%$ Confidence Interval for Mean } \\
\cline { 3 - 7 } & $\mathrm{N}$ & Mean & SD & SE & Lower Bound & Upper Bound \\
\hline No participation & 24 & 3.917 & 1.6061 & .3279 & 3.238 & 4.595 \\
Yes participation & 14 & 5.186 & 1.3553 & .3622 & 4.403 & 5.968 \\
Total & 38 & 4.384 & 1.6229 & .2633 & 3.851 & 4.918 \\
\hline
\end{tabular}

Cross tabulations show that there is a statistically significant relationship between professional experience and participation in information events $(\mathrm{Phi}=0.434 ; p=0.006)$. In particular, the majority of those working in sectors that have to address extreme events have participated in information events (64.7\%), whereas participation in such events by individuals who work in sectors vulnerable to extreme events is in the minority $(21.7 \%)$.

To what extent does intense personal experience of extreme weather events influence the level of concern?

This variable captures whether or not the individual described an intense, life-threatening experience with extreme weather event in the past, following the first theme identified in the qualitative analysis. ANOVA analysis shows that there is a statistically significant positive relationship between intensity of experience lived, and level of concern about extreme weather events $(F(1.38)$ $=5.155 ; p=0.029)$. Individuals who have had an intense, lifethreatening experience related to extreme weather report being concerned more on average $(M=4.7 ; \mathrm{SD}=1.05)$ than those who have not experienced such an event $(M=3.4 ; \mathrm{SD}=1.84)$. In Table 2 , the descriptive statistics of the analysis can be seen, including the confidence intervals.

\section{Which factors influence the level of concern about extreme weather events?}

A stepwise regression was carried out, including all the independent variables above. Personal intense experience was the only significant determinant of concern $($ Beta $=0.428 ; t=2.840$; $p=0.007)$ in the model. The model explained $16 \%$ of the variance of the dependent variable (Adj $R^{2}=0.16$ ). Individuals with experience of an extreme life-threatening event are more concerned on average than those without such an experience. No other variable was a significant predictor.

\section{DISCUSSION}

The respondents in our sample describe their experiences with extreme weather in three broad ways: personal and emotional, most often under life-threatening circumstances, and feelings of loss of control and fear; personal but descriptive, without any emotions; and, finally in an impersonal way, sometimes relying on the availability heuristic. Several of them are aware of the subjective element of acknowledging a weather event as extreme. Statistical analyses indicate that among the variables studied here only the life-threatening intense experience is significantly related to concern about extreme weather events, whereas the secondary experience via information events or professional relationship to extreme events seems to play no role in concern. The variance explained by the model is quite low, which indicates that we still do not know much about the determinants of the level of concern.
Concern about extreme events is very much linked to the availability heuristic, and thus system 1 thinking, which operates automatically with little effortful control (Kahneman 2003). This seems to function in two different ways: first, individuals who have experienced a life-threatening event can more easily recall this experience and thus they report a higher level of concern about extreme events than those without such an experience. At the same time, for those individuals without personal lifethreatening experience, their first response often conveys the extreme event experienced most recently, e.g., the previous year.

Our results need to be treated with care as the sample was small, with 40 individuals, and not random. Most of our respondents were professionals, in professions either responding to extreme weather, or being affected by extreme weather. However, using a smaller sample, we aimed at integrating more indepth understanding of individuals' experiences of extreme events with robust statistical analysis, and indepth interviews were a good methodological choice for that purpose. Furthermore, targeting professions with different relationships to extreme weather is also important to understand the possible impact that professional involvement has on the level of concern. We cannot preclude that the interviewees were more than average informed and interested in the topic: they indicated their willingness to participate after being introduced to the topic of the survey. Nevertheless, our results show that individuals may have had personal experience with an extreme event, but only if they felt threatened by this extreme event did this raise their concern about extreme events. In this respect, we provide a more nuanced understanding of the type of personal experience with an extreme event that affects concern. It is assigning experiences with emotions and feelings that is of relevance to and makes a difference for concern, and not simply the experience itself. Future research should include broader surveys, especially distinguishing among different types of emotions related to previous experiences with concern about extreme events. Such surveys could also ask for explicit data on willingness to support and preparedness for adaptation measures.

As concern about extreme events is important for adaptation decisions, both at the organizational as well as the household level, prioritization of adaptation decisions can be expected to be greater among individuals who attach emotions to their earlier experience, which suggests a random element, and limited intervention possibilities. The same holds for support for largerscale adaptation measures and policies. Communication at information events and workshops has a limited impact on concern, if at all, consistent with previous studies (Kellstedt et al. 2008, Kellens et al. 2012). However, if such communication events are targeted toward conveying personal circumstances as well as emotions of individuals who have experienced similar events, this could be different. Our results suggest the primary role of life- 
Table 2. ANOVA descriptives for impact of intense experience on level of concern

\begin{tabular}{|c|c|c|c|c|c|c|}
\hline & \multirow[b]{2}{*}{$\mathrm{N}$} & \multirow[b]{2}{*}{ Mean } & \multirow[b]{2}{*}{ SD } & \multirow[b]{2}{*}{ SE } & \multicolumn{2}{|c|}{$95 \%$ Confidence Interval for Mean } \\
\hline & & & & & Lower Bound & Upper Bound \\
\hline No intense experience & 28 & 3.411 & 1.8462 & .3489 & 2.695 & 4.127 \\
\hline Yes intense experience & 12 & 4.708 & 1.0544 & .3044 & 4.038 & 5.378 \\
\hline Total & 40 & 3.800 & 1.7424 & .2755 & 3.243 & 4.357 \\
\hline
\end{tabular}

threatening experience and emotional responses on concern, which can help inform design of adaptation workshops and information events. Inviting individuals with personal experience to convey their experiences in such events and relating the adaptation decisions to specific emotions can help link in the participants' minds someone else's life-threatening experience with their own reality. The attention in such information events could shift from professionals of extreme weather and their factual information to real-life experts of extreme weather and their emotions about the events. Recent work also suggests that transmission of sound scientific information is unlikely to raise concern about climate change risks (Kahan et al. 2012).

Another step for raising concern about extreme events could be designing different information events on the basis of the background of their participants. The qualitative analysis shows that some individuals relate to and describe their experiences in a personal (but not an emotional) way, and when communicating with those individuals it would perhaps be useful to link to specific emotions in different personal circumstances. For instance, being on the road, being stuck outdoors or indoors, and the feeling of helplessness, despair, and loss of control, the fear for one's and others' lives, or the feeling of wanting to overcome the natural force. Techniques such as role-playing games or focusing on imagining a concrete weather event and one's own role can help in eliciting the participants' emotions. For other individuals, namely those with impersonal and descriptive responses, the different personal circumstances also need to be brought to the fore or be cultivated (i.e., the location of the experience, alone or with others, different extreme events, clothing and other gear, etc.) alongside different emotions. Techniques that invoke imagination can help here as well. A previous study suggested that games as decision-support tools in the context of climate change adaptation that focus on enhancing the memory (e.g., experiences with past climatic extremes) can increase individual and collective anticipatory capacity among participants (Tschakert and Dietrich 2010).

The availability heuristic can also be used during such information events. Reminding participants of more or less recent key events, e.g., for The Netherlands, the heat wave of 2003 or the flooding of 1953, which may have been experienced by older family members, asking participants to remember under which circumstances they experienced them and how it felt, can be used as a reference point in such communication events. A practical example of this is that in recent years in The Netherlands, when discussing meteorolgy, reference years and past extreme weather events are starting to being used to communicate with the public about weather and climate change (Platform Communication on Climate Change (PCCC) 2011).
As concern about extreme events is linked to intense, threatening personal experiences of such events, it can be expected that support for adaptation measures and policies at all levels also has a random and ad hoc component, with limited intervention possibilities. From a communications point of view, linking the proposed adaptation measure to specific reference events as mentioned above, as well as to the intense emotions it has evoked in different individuals can also help gain support and legitimacy. Adaptation measures tend to be framed generally with factual information and cost-benefit analyses, whereas the role of personal circumstances and emotions is almost never conveyed.

Although climate change-related risk perceptions can influence adaptation decisions, high risk perceptions do not, by themselves, automatically trigger protective behavior. For example. protection motivation theory postulates that, in addition to high threat appraisal (risk perceptions), individuals should have high coping appraisals before they protect themselves against a risk (Bubeck et al. 2012, 2013). High coping appraisal is present if individuals perceive the protection measure as effective in coping with the threat (response efficacy), if they expect that the measures are not too costly or time consuming to implement (response costs), and if individuals think that it is relatively easy for them to install the measure (self-efficacy). According to Swim et al. (2011a, b), direct, indirect, or mediated experiences with impacts of climate change influence both threat and coping appraisals. Moreover, such experiences trigger affective responses, such as fear, anxiety, or worry, which will influence individual appraisals alongside of individual attributions for the causes of the experience. Resulting responses could be the seeking of information about risk or protection measures, or eventually an investment in a protective measure (e.g., buy insurance), whereas a non-protective response may result, for example, if the individual denies the risk.

Although this paper has focused on weather-related risk perceptions, which can influence adaptation behavior, and not on particular behavioral responses, different types of adaptation behavior can emerge from climate risk perceptions. For example, Stern (2000) differentiated between four types of environmental behavior, namely: environmental activism, nonactivist behavior in the public sphere, private-sphere environmentalism, and other behavior such as influencing the actions of organizations to which individuals belong. Future research can aim to identify such behavioral typologies for adaptation and examine how these relate to perceived climate risk perceptions. Nevertheless, our results suggest that communicating adaptation measures in relation to different personal circumstances and strong emotions, especially at the household, the organizational level, and the sectorial level, can help mobilize support for the measures and gain legitimacy. As actors engage in struggles in providing relevant frames of 
adaptation, this specific frame emphasizes the individual citizen and his or her role in adaptation governance.

\section{CONCLUSION}

Several extreme weather adaptation plans are currently being designed and implemented by national and local governments as well as by organizations and sectors. An important issue is how to raise an adequate level of concern among individuals, policy makers, and broader decision makers in companies and organizations, so that adaptation to extreme events becomes mainstream practice. We conducted 40 indepth interviews with individuals from different sectors in The Netherlands in order to identify the different types of experiences with extreme events, as well as the link between such experiences and level of concern. Our results indicate that individuals who have experienced an intense, life-threatening event have a higher level of concern than those who have not. Professional experience and secondhand experience in participation in information events do not seem to affect the level of concern about extreme events. This suggests limited intervention possibilities for communication of adaptation, as well as for raising support for adaptation measures. Framing adaptation measures in relation to personal circumstances and emotions during extreme events could help raise concern about extreme weather events, as well as societal support for adaptation measures.

Responses to this article can be read online at: http://www.ecologyandsociety.org/issues/responses. $\mathrm{php} / 6474$

\begin{abstract}
Acknowledgments:
The paper is based on work carried out in the project "Bridging the Gap," funded by Netherlands Organisation for Scientific Research (NWO) and Knowledge for Climate (KvK), project number 830.10.005, and a VENI grant from NWO. We would like to thank Channah Betgen and Iris de Hoog for valuable data-gathering work and Arthur C. Petersen, Matthijs Hisschemoeller, Erik Min, and Wilco Hazeleger for their feedback during the project. We would like to thank two anonymous reviewers for their comments on the text.
\end{abstract}

\section{LITERATURE CITED}

Aerts, J. C. J. H., and W. J. W. Botzen. 2011. Climate-resilient waterfront development in New York City: Bridging flood insurance, building codes, and flood zoning. Annals of the New York Academy of Sciences 1227:1-82.

Aerts, J. C. J. H., W. J. W. Botzen, M. J. Bowman, P. Ward, and P. Dircke, editors. 2011. Climate adaptation and flood risk in coastal cities. Earthscan, London, UK.

Ajzen, I. 1991. The theory of planned behavior. Organizational Behavior and Human Decision Processes 50:179-211.

Archie, K. M., L. Dilling, J. B. Milford, and F. C. Pampel. 2012. Climate change and western public lands: a survey of US federal land managers on the status of adaptation efforts. Ecology and Society 17(4): 20. DOI: http://dx.doi.org/10.5751/ES-05187-170420/
Botzen, W. J. W., J. C. J. H. Aerts, and J. C. J. M. van den Bergh. 2009. Dependence of flood risk perceptions on socio-economic and objective risk factors. Water Resources Research 45: W10440. http://dx.doi.org/10.1029/2009WR007743

Botzen, W. J. W., and J. C. J. M. van den Bergh. 2012a. Monetary valuation of insurance against flood risk under climate change. International Economic Review 53:1005-1025.

Botzen, W. J. W., and J. C. J. M. van den Bergh. 2012b. Risk attitudes to low-probability climate change risks: WTP for flood insurance. Journal of Economic Behavior and Organization 82:151-166.

Brody, S. D., S. Zahran, A. Vedlitz, and H. Grover. 2008. Examining the relationship between physical vulnerability and public perceptions of global climate change in the United States. Environment and Behavior 40:72-95.

Bubeck, P., W. J. W. Botzen, and J. C. J. H. Aerts. 2012. A review of risk perceptions and other factors that influence mitigation behavior. Risk Analysis 32:1481-1495.

Bubeck, P., W. J. W. Botzen, H. Kreibich, and J. C. J. H. Aerts. 2013. Detailed insights into the influence of flood-coping appraisals on mitigation behaviour. Global Environmental Change 23(5):1327-1338. http://dx.doi.org/10.1016/j.gloenvcha.2013.05.009

Bulkeley, H. 2010. Cities and the governing of climate change. Annual Review of Environment and Resources 35:229-253.

Burn, D. H. 1999. Perceptions of flood risk: a case study of the Red River flood of 1997. Water Resources Research 35:34513458 .

Dessai, S., W. N. Adger, M. Hulme, J. Turnpenny, J. Köhler, and R. Warren. 2004. Defining and experiencing dangerous climate change. Climatic Change 64:11-25.

Dupuis, J., and P. Knoepfel. 2013. The adaptation policy paradox: the implementation deficit of policies framed as climate change adaptation. Ecology and Society 18(4): 31. DOI: http://dx.doi. org/10.5751/ES-05965-180431

Finucane, M. L., A. Alhakami, P. Slovic, and S. M. Lohnson. 2000a. The affect heuristic in judgements of risks and benefits. Journal of Behavioral Decision Making 13:1-17.

Finucane, M. L., P. Slovic, C. K. Mertz, J. Flynn, and T. A. Satterfield. 2000b. Gender, race, and perceived risk: the "white male" effect. Health, Risk and Society 2:159-172.

Fischhoff, B., P. Slovic, and S. Lichtenstein. 1982. Lay foibles and expert fables in judgments about risk. The American Statistician 36:240-255.

Flynn, J., P. Slovic, C. K. Mertz, and C. Carlisle. 1999. Public support for earthquake risk mitigation in Portland, Oregon. Risk Analysis 19:205-216.

Howell, R. A. 2014. Investigating the long-term impacts of climate change communications on individuals attitudes and behavior. Environment and Behavior 46:70-101.

Kahan, D. M., E. Peters, M. Wittlin, P. Slovic, L. L. Ouellette, D. Braman, and G. Mandel. 2012. The polarizing impact of science literacy and numeracy on perceived climate change risks. Nature Climate Change 2:732-735. 
Kahneman, D. 2003. Maps of bounded rationality: psychology for behavioral economics. The American Economic Review 93:1449-1475.

Kahneman, D., P. Slovic, and A. Tversky. 1982. Judgment under uncertainty: heuristics and biases. Cambridge University Press, Cambridge, UK. http://dx.doi.org/10.1017/CBO9780511809477

Kellens, W., T. Terpstra, and P. D. Maeyer. 2012. Perception and communication of flood risks: a systematic review of empirical research. Risk Analysis 33(1): 24 49. 10.1111/j.1539-6924.2012.01844. $\underline{\mathrm{x}}$

Keller, C., M. Siegrist, and H. Gutscher. 2006. The role of the affect and availability heuristics in risk communication. Risk Analysis 26:631-639.

Kellstedt, P. M., S. Zahran, and A. Vedlitz. 2008. Personal efficacy, the information environment, and attitudes toward global warming and climate change in the United States. Risk Analysis 28:113-126.

Leiserowitz, A. 2005. American risk perceptions: is climate change dangerous? Risk Analysis 25:1433-1442.

Leiserowitz, A. 2006. Climate change risk perception and policy preferences: the role of affect, imagery, and values. Climatic Change 77:45-72

Loewenstein, G. F., C. K. Hsee, E. U. Weber, and N. Welch. 2001. Risk as feelings. Psychological Bulletin 127:267-286.

Lowe, T. D., K. Brown, S. Dessai, M. de França Doria, K. Haynes, K. Vincent. 2006. Does tomorrow ever come? Disaster narrative and public perceptions of climate change. Public Understanding of Science 15: 435-457.

Lowe, T. D., and I. Lorenzoni. 2007. Danger is all around: eliciting expert perceptions for managing climate change through a mental models approach. Global Environmental Change 17:131-146.

Michel-Kerjan, E., S. Lemoyne de Forges, and H. Kunreuther. 2012. Policy tenure under the U.S. National Flood Insurance Program (NFIP). Risk Analysis 32:644-658.

Mozumder, P., E. Flugman, and T. Randhir. 2011. Adaptation behavior in the face of global climate change: survey responses from experts and decision makers serving the Florida Keys. Ocean and Coastal Management 54:37-44.

Nolan, J. M. 2010. "An inconvenient truth" increases knowledge, concern, and willingness to reduce greenhouse gases. Environment and Behavior 42:643-658.

Peacock, W. G., S. D. Brody, and W. Highfield. 2005. Hurricane risk perceptions among Florida's single family homeowners. Landscape and Urban Planning 73:120-135.

Platform Communication on Climate Change (PCCC). 2011. De staat van het klimaat 2010. Platform Communication on Climate Change (PCCC), de Bil, Wageningen, The Netherlands.

Poortinga, W., L.Steg, and C. Vlek. 2002. Environmental risk concern and preferences for energy-saving measures. Environment and Behavior 34:455-478.
Reynolds, T. W., A. Bostrom, D. Read, and M. G. Morgan. 2010. Now what do people know about global climate change? Survey studies of educated laypeople. Risk Analysis 30:1520-1538.

Rogers, R. W. 1973. A protection motivation theory of fear appeals and attitude change. The Journal of Psychology 91:93114.

Rogers, R. W. 1983. Cognitive and physiological processes in fear appeals and attitude change: a revised theory of protection motivation. Pages 153-176 in B. L. Cacioppo and R. E. Petty, editors. Social psychophysiologv: a sourcebook. The Guilford Press, London, UK.

Sjöberg, L. 1999. Consequences of perceived risk: demand for mitigation. Journal of Risk Research 2:129-149.

Sjöberg, L. 2000. Consequences matter, "risk" is marginal. Journal of Risk Research 3:287-295.

Slovic, P. 1987. Perception of risk. Science 236:280-285.

Slovic, P. 2000. Perceptions of risk. Earthscan, London, UK.

Slovic, P., M. L. Finucane, E. Peters, and D. G. MacGregor. 2004. Risk as analysis and risk as feelings: some thoughts about affect, reason, risk, and rationality. Risk Analysis 24:311-322.

Stern, P. C. 2000. Toward a coherent theory of environmentally significant behavior. Journal of Social Issues 56:407-424.

Strauss, A., and J. Corbin. 1990. Basics of qualitative research; grounded theory procedures and techniques. Sage, Newbury Park, California, USA.

Swim, J., S. Clayton, T. Doherty, G. Gifford, G. Howard, J. Reser, P. Stern, and E. Weber. 2011a. Psychology and global climate change: addressing a multi-faceted phenomenon and set of challenges. Report of the American Psychological Association Task Force on the Interface Between Psychology and Global Climate Change. American Psychological Association, Washington, D.C., USA. [online] URL: http://www.apa.org/ science/about/publications/climate-change-booklet.pdf

Swim, J. K., P. C. Stern, T. J. Doherty, S. Clayton, J. P. Reser, E. U. Weber, R. Gifford, and G. S. Howard. 2011b. Psychology's contribution to understanding and addressing global climate change. American Psychologist 66:241-250.

Terpstra, T., M. K. Lindell, and J. M. Gutteling. 2009. Does communicating (flood) risk affect (flood) risk perceptions? Results of a quasi-experimental study. Risk Analysis 29:11411155 .

Tschakert, P., and K. A. Dietrich. 2010. Anticipatory learning for climate change adaptation and resilience. Ecology and Society 15: 11. [online] URL: http://www.ecologyandsociety.org/vol15/iss12/ art11/

Tversky, A., and D. Kahneman. 1973. Availability: a heuristic for judging frequency and probability. Cognitive Psychology 5:207232.

Tversky, A., and D. Kahneman. 1974. Judgment under uncertainty: heuristics and biases. Science 211:1124-1131. 
van Dorland, R., B. Jansen, K. van der Sandt, B. van Hove, C. Jacobs, C., and R. Swart, R. 2011, Staat van het klimaat 2010 : actueel onderzoek en beleid nader verklaard. PCCC, de Bil, Wageningen, The Netherlands.

Vasileiadou E., M. Hisschemoeller, A. C. Petersen, C. Betgen, W. Hazeleger, I. de Hoog, and E. Min. 2014. Adaptation to extremes: Identifying different societal perspectives in the Netherlands. Regional Environmental Change 14(1):91-101. http://dx.doi. org/10.1007/s10113-013-0460-4

Viscusi, W. K., and R. J. Zeckhauser. 2006. National survey evidence on disasters and relief: risk beliefs, self-interest, and compassion. Journal of Risk and Uncertainty 33:13-36.

Wamsler, C., E. B. Brink, and O. Rentala. 2012. Climate change, adaptation, and formal education: the role of schooling for increasing societies' adaptive capacities in El Salvador and Brazil. Ecology and Society 17(2):2. DOI: http://dx.doi.org/10.5751/ ES-04645-170202

Weber, E. U. 2006. Experience-based and description-based perceptions of long-term risk: why global warming does not scare us (yet). Climatic Change 77:103-120.

Whitmarsh, L. 2008. Are flood victims more concerned about climate change than other people? The role of direct experience in risk perception and behavioural response. Journal of Risk Research 11:351-374. 